\title{
The Potential of Florida Lychee to Cross Over to American Consumers: An Industry Perspective ${ }^{1}$
}

\section{A.R. Rafie, Carlos Balerdi, Jonathan Crane ${ }^{2}$ \\ Overview of the Lychee Industry in Florida}

Lychee, a subtropical fruit, is native to southern China, where it has been cultivated for thousands of years and is considered a very important crop in terms of both economic and cultural value. Lychee was introduced to Florida in 1880 in Sanford. In 1903, an American missionary named Brewster brought the 'Chen Purple' cultivar (cv.) from China to Florida, where it was propagated and distributed to growers as the 'Brewster' cultivar. This cultivar made a significant contribution to developing the Florida lychee industry. Currently, the major lychee cultivar grown in Florida is 'Mauritius'. Growers prefer the 'Mauritius' cultivar because the fruit can be harvested 2-3 weeks earlier than that of the 'Brewster' cultivar, enabling them to sell the fruit when market prices are higher. Also, the 'Mauritius' cultivar is believed to be more reliable in terms of producing fruit every year in comparison to 'Brewster'. In 2006, approximately 800 acres of lychee were grown in South Florida, mostly in Miami-Dade County. Florida lychees are only available from late May to early July and are mainly sold fresh to Asian markets, mostly along the east coast of the United States. Before lychees were allowed to be imported to the United States, Florida lychee growers enjoyed higher prices. However, in recent years, U.S. lychee prices have declined and growers now have to compete with imported lychee from Mexico, Taiwan, China and Israel. In 2005, Hurricanes Wilma and Katrina caused severe structural and consequently economic damage to most of the tropical fruits grown in Miami-Dade County. Lychee groves were severely affected by strong winds and flooding. The effect of Katrina and Wilma continued in 2006, combined with warmer than usual weather conditions in the fall of 2006 and part of January 2007. Lychee production remains significantly lower than it was before the hurricanes of 2005. The lower prices resulting from imported lychees, combined with low productivity in recent years, have caused some growers to question the economic viability of lychee production in Miami-Dade County. However, there are other growers who believe lychee is a very unique fruit with considerable potential to cross over to American consumers. These growers feel that the American lychee market can be greatly expanded.

1. This document is HS1112, one of a series of the Horticultural Sciences Department, Florida Cooperative Extension Service, Institute of Food and Agricultural Sciences, University of Florida. Original publication date August, 2007. Visit the EDIS Web Site at http://edis.ifas.ufl.edu.

2. A.R. Rafie, Horticulture Extension Specialist, Virginia State University, Petersburg, Virginia and former Extension Agent, Miami-Dade County South Extension Office, Homestead, Florida; Carlos Balerdi, Extension Agent, Miami-Dade County South Extension Office, Homestead, Florida; and Jonathan Crane, Professor, Department of Horticultural Sciences, Tropical Research and Education Center, Homestead, Florida. 
A survey of lychee growers, packers, shippers, wholesalers and retailers was conducted to determine their assessment of lychee's potential to appeal to American consumers and eventually become as popular as other tropical fruits such as pineapple and mango. The purpose of this article is to present the findings of this survey.

\section{Consumer Survey Results}

In 2003, a consumer survey was conducted with consumers residing in Broward and Miami-Dade Counties to determine the acceptance of lychee among consumers. In this study, a sample of lychee fruit was provided to participants. They were asked if they knew that lychee was grown in Florida; $41 \%$ of the respondents said "No." (Figure 1). When the respondents were asked if they had seen lychee in their local supermarkets before, $75 \%$ said "No" (Figure 2). After trying a sample of lychee fruit, participants were asked if they liked lychees or not, and $91 \%$ of them indicated they did like them. Six percent said they did not, and three percent said they were not sure (Figure 3).

\section{Industry Survey Results}

In 2007, a survey of Miami-Dade County lychee growers, packers, shippers, wholesalers and retailers that sell lychee at the national level was conducted. The Produce Blue Book was used to obtain a list of wholesalers and retailers. The survey listed a total of 16 production, post-harvest and marketing factors that were considered to limit lychee fruits from crossing over to American consumers. Respondents were asked to select only 10 of these factors and to rank them from 1 to 10 in order of importance (1 being very important and 10 not important at all). A total of 350 questionnaires were either faxed or e-mailed to potential industry respondents. A total of 50 questionnaires were returned for a response rate of $14 \%$. The results of the survey were sorted and presented as representing either growers or non-growers according to the information they provided. If a grower also packed and/or shipped lychee, he/she was considered as a grower.

When respondents were asked, "Given the right conditions and effort, do you believe that lychee has the potential to become as popular as other tropical fruits such as pineapple and mango among American consumers," $80 \%$ of the growers said "Yes" in comparison to 59\% of the non-growers (Figure 4). This indicated that growers are somewhat more optimistic about the future market prospect for lychee than non-growers. When respondents were asked to rank production, postharvest and marketing factors that in their opinion limited lychee from becoming as popular as pineapple and mango among American consumers, growers selected "lack of year-round availability", "lack of consumer awareness", and "lack of sufficient investment in promotion and advertising" as the top three most important reasons. For non-growers the top three factors were "lack of consumer awareness", "lack of year-round availability", and "expensive at the retail level."

Growers also considered factors such as "low production /acre (low yield)", "profitability is too low as production forecast is erratic", and "inadequate post harvest treatments to extend shelf life" to be important in limiting lychee from becoming as popular as pineapple and mango among American consumers. Non-growers considered "inadequate domestic supply" and "lack of information about this fruit among wholesalers and retailers" also important.

Based on all respondents opinions, "lack of year-round availability" and "lack of consumer awareness" are top priorities to consider if the lychee industry in Florida plans to fully promote lychee among American consumers. The "lack of year-round availability" factor depends on selecting new cultivars that produce fruit out of season and/or identifying horticultural techniques to manipulate current lychee cultivars grown in Florida to produce fruit out of season (off-season flower inducement for other fruit crops such as mango and longan are a common practice, which is done by applying certain types of fertilizers at specific times of the growing season). Further, considerable investment is needed to create consumer awareness in the United States. Creation of a partnership among Florida growers and exporting countries may be feasible to assure sufficient funding to promote lychee in the United States. 


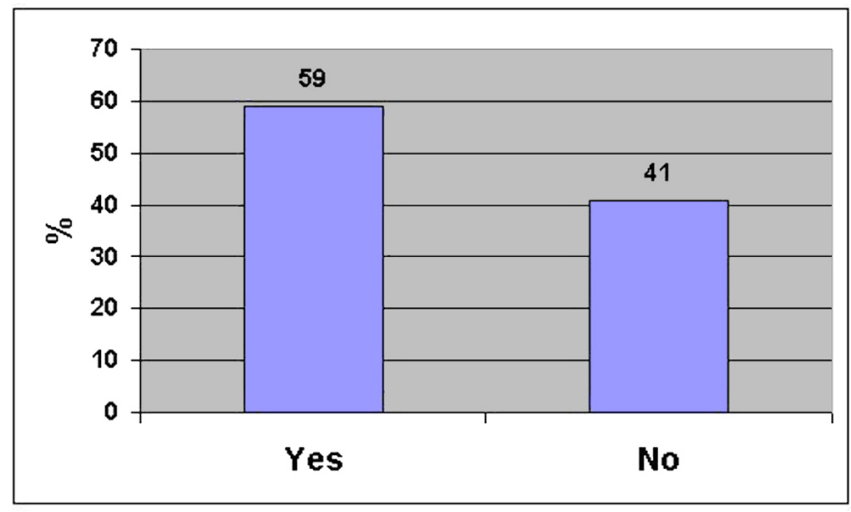

Figure 1. Percentages of respondents that knew lychee is being grown in Florida.

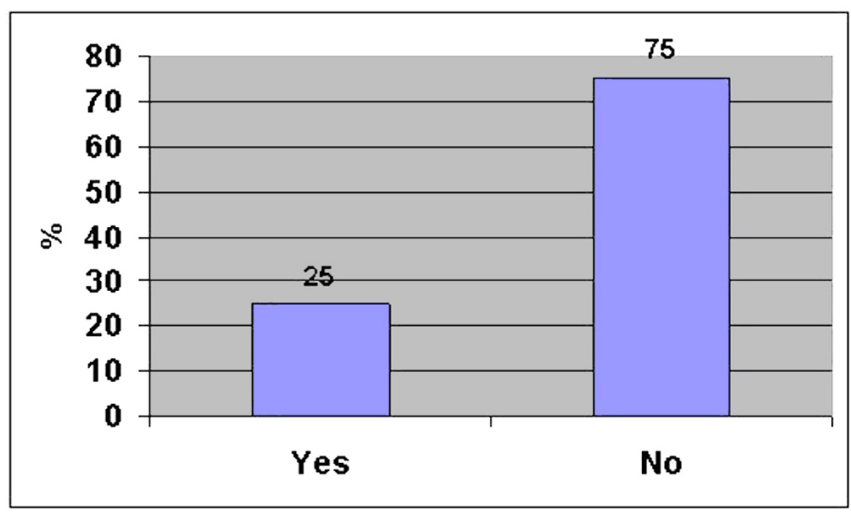

Figure 2. Percentages of respondents that had seen lychee fruit in local supermarkets.

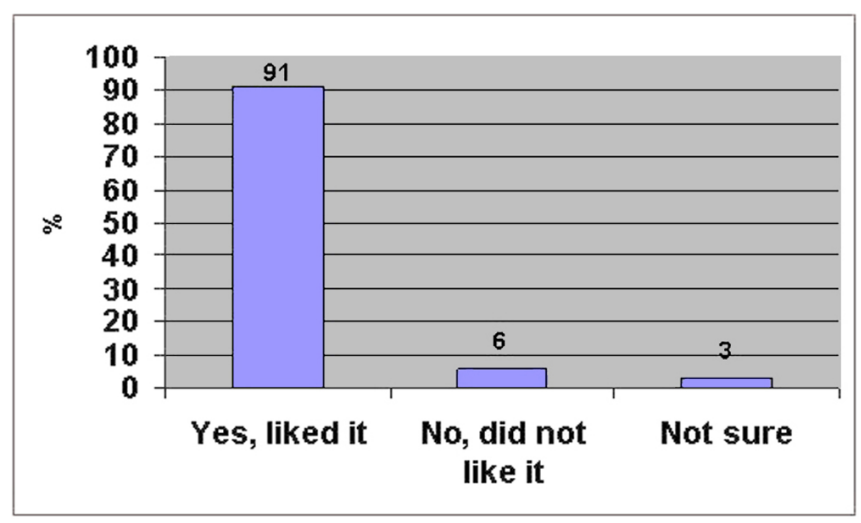

Figure 3. Respondents' evaluations of a sample of lychee fruit.

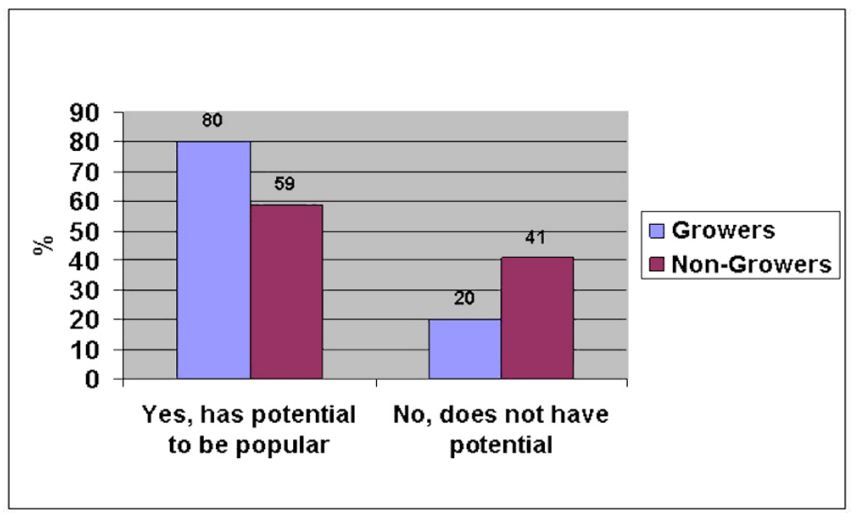

Figure 4. Percentages of growers and non-growers that believe that lychee has the potential to become as popular as other tropical fruits such as banana, pineapple, and mango among American consumers. 